\title{
Yielding behaviour of cemented binary mixture
}

\author{
Sathya Subramanian ${ }^{1}$ and Taeseo $\mathrm{Ku}^{1, *}$ \\ ${ }^{1}$ National University of Singapore, Department of Civil and Environmental Engineering, 117576, Singapore
}

\begin{abstract}
Cement stabilization is commonly used for improving soft soils and the mechanical behaviour of cemented pure clay has been well documented. However, limited studies have investigated the effect of sand in a cement-clay matrix because the conventional water to solid (solid includes soil and cement) ratio cannot be simply used to characterize the behaviour of cemented binary mixture. The water holding capacity of the mixture reduces with increase in sand content, when the water to solid ratio is kept constant. In this study, the ratio of water to clay and cement is kept constant, so that the effect of sand content could be studied. The materials used in this study are kaolin clay, sand with $\mathrm{D}_{50}$ of $0.71 \mathrm{~mm}$ and Ordinary Portland cement type 1 . Sand content varies from $0 \%$ to $50 \%$ and curing time is kept constant at 7 days. We used three ratios of water to clay and cement which correspond to $139 \%, 104 \%$ and $78 \%$. The isotropic yield point increases with increase in sand content and cement content, while it reduces with increase in water content. A power function captures the variation of yield point with the ratio of water to cement and clay.
\end{abstract}

\section{Introduction}

The mechanical properties of pure clay and pure sand have been studied thoroughly over the years. But, in-situ condition is closer to a mixture of clay, sand or silt. The properties of these binary mixtures are different from those pure clay or pure sand [1-6]. Literatures on the strength, stiffness and compressibility of these natural or untreated binary mixtures are available in abundant.

Marine clay is prevalent in the eastern part of Singapore, which has low strength and high compressibility. During underground excavation for construction of tunnels and caverns, the dredged soil consists of mostly marine clay, which has high sand content and water content. In a densely populated country like Singapore, land reclamation is often required to relieve land stress. The cost of imported sand used for land reclamation has escalated in recent years. Thus, the unwanted soils from excavations are also considered for land reclamation. Since the low strength and high compressibility of these materials make it difficult to be used for geotechnical application, chemical stabilization through cement mixing is often carried out to improve the properties of these geomaterials.

Ordinary Portland cement is widely used for ground improvement. Basically, the hydration forms cementitious products like calcium silicate hydrates that bind the particles together. Many studies have been conducted on cemented clay investigating the structure [7-9], strength [10-16], compressibility [17-20], triaxial behaviour [21-23] and stiffness[24,25]. However, these studies have focussed on the behaviour of pure cemented clay or sand, although in-situ soil is seldom homogeneous. As discussed above, the dredged materials often contain marine clay mixed with sand. Chian et al. [26] found that the free water to cement ratio $\left(w / w_{L}\right) / c$ is a key parameter to study the strength evolution of cemented binary mixture. Subramanian and $\mathrm{Ku}$ [27] found that the increase in strength and stiffness of cemented binary mixture at a given free water to cement ratio was attributed to the combined effect of water and sand in the mix. The effect of sand in the cemented clay matrix has not been exclusively studied yet. Therefore, the first objective of this study is to define sand content, water content, and cement content in such a way that the effect of sand in the cemented clay matrix could be studied. Once the terminologies are established, this study further investigates the isotropic compression behaviour of cemented binary mixture in triaxial testing conditions.

\section{Methodology}

Subramanian and $\mathrm{Ku}$ [27] discussed that the use of conventional water to solids definition can lead to reduction in strength with increase in sand content and further concluded that the use of free water to cement ratio led to increase in strength which was contributed by both water and cement. The authors did not discuss in detail on the issue. This study provides more in depth discussion with the help of phase relationship as shown in Fig. 1. In this study, case 1 refers to the conventional water content definition which is the ratio of the mass of water to the total mass of solids and the conventional cement content definition which is the ratio of the mass

\footnotetext{
* Corresponding author: ceekt@nus.edu.sg
} 
of cement to the total mass of soil. Case 1 was discussed in detail by Subramanian and $\mathrm{Ku}$ [27]. In case 2, the cement content is based on the total mass of soil, while water content is defined in terms of free water to cement ratio. The difference between case 1 and case 2 is the definition of water content. In case 2 , the free water to cement ratio is kept at 1.2 for all binary mixtures and cement content is fixed, while in case 1 , the water to solids ratio was kept at $104 \%$. For case 2, the mass of water required to prepare the sample can be calculated knowing the liquid limit of each binary mixture. In case 3 , cement content is defined as the ratio of the mass of cement to the mass of clay and water content is the ratio of the mass of water to the mass of clay.

In order to come up with phase diagram (Fig. 1) corresponding to each case study, the mass of each constituent in a sample should be known. For this purpose, two sacrificial samples (to ensure repeatability) are prepared for each case study, with cement content of $30 \%$ and sand content of $30 \%$. The water content is measured immediately after mixing the sample. The initial weight and volume are measured. Immediately after sample preparation, the sample was washed in $75 \mu \mathrm{m}$ sieve, so that mass of sand retained can be calculated. For example, the phase relationship for case 2 was obtained as follows:

-Total Mass $(\mathrm{TM})=M_{c}+M_{s a}+M_{c e m}+M_{w}$

where $M_{c}, M_{s a}, M_{c e m}$ and $M_{w}$ are mass of clay, sand, cement and water, respectively. $M_{c}$ is known from sieve analysis.

$\circ M_{w}=w \times\left(M_{c}+M_{s a}+M_{c e m}\right)$

where $w$ is the water content.

${ }^{\circ} M_{c e m}=0.3 \times\left(M_{c}+M_{s a}\right)$

$\circ \mathrm{TM}=M_{c}+M_{s a}+\left[0.3 \times\left(M_{c}+M_{s a}\right)\right]+w \times\left[1.3 \times\left(M_{c}+M_{s a}\right)\right]$

The volume corresponding to each phase is calculated knowing the specific gravity of each material.

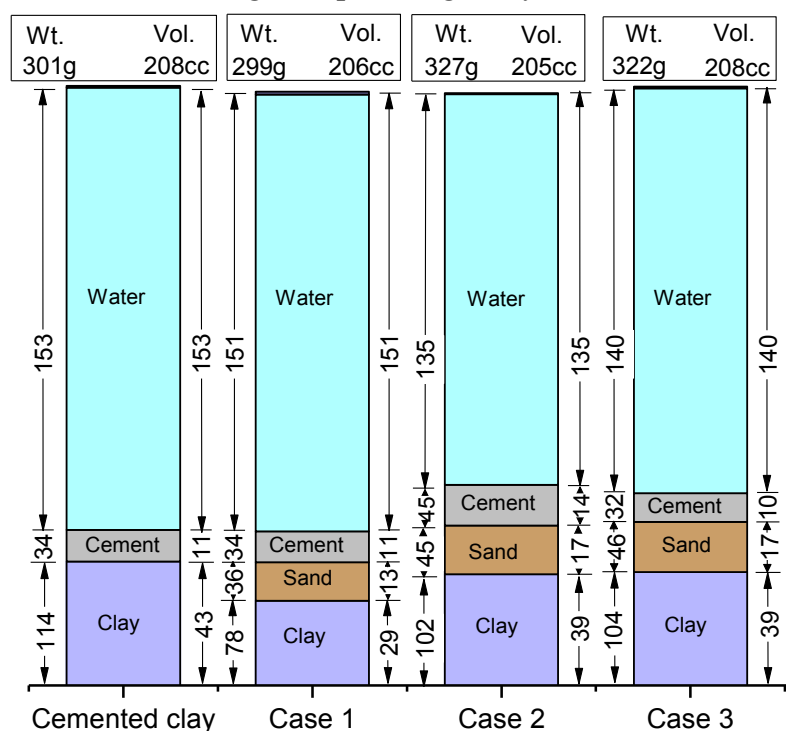

Fig. 1. Phase relationship for binary mixture.
By this definition (case 2), there is an additional amount of cement available as compared to the reference cemented clay mixture, due to presence of sand. Also, the $45 \mathrm{~g}$ of sand added to the mixture did not replace equal proportions of clay, water and cement. So, in case 2 , the ratio of water to combined sum of clay and cement has reduced when compared to the cemented clay.

To study the effect of sand in cemented binary mixture, the sand should replace equal proportions of clay, cement and water, so that the ratio of water to combined sum of clay and cement would be comparable to that of cemented clay as shown in case 3 . When comparing the reference cemented clay and the binary mixture in case 3 , the strength of the host cemented clay is maintained (the ratios of clay, cement and water present in both are same), while, any increase or decrease in strength would be possible only due to the presence of sand. Further isotropic triaxial tests have been carried out following the case 3 terminologies.

\section{Materials and sample preparation}

Kaolin clay is used in this study, which has a liquid limit of $80 \%$. The sand used is uniformly graded and classified as 'SP' according to Unified Soil Classification System. The $D_{50}$ and $D_{10}$ of the sand are $0.71 \mathrm{~mm}$ and $0.45 \mathrm{~mm}$, respectively. Ordinary Portland cement Type I is used as binding admixture whose major constituents are alite $(63 \%)$ and belite $(24.3 \%)$. The sand content in this study is defined as the mass of sand in the total mass of the soil.

The sample preparation involves four stages of mixing. After the required amount of clay, sand, cement and water are taken, some water is added to the dry clay and mixed for 5 minutes. Then sand is added to the wet clay and mixed for 5 minutes. Then cement is added to the mixture and mixed for 5 minutes. Finally, the remaining water is added, and the mixing is carried out for 5 minutes. After mixing, the homogeneous mixture is transferred into the PVC moulds of $50 \mathrm{~mm}$ diameter and $100 \mathrm{~mm}$ long in three layers. The entrapped air voids are removed by tamping the soil. Then, the top and bottom surface of the sample is trimmed and covered in plastic covers to keep inside water for curing. After 7 days of curing, the samples are extracted from the PVC moulds and the bulk density of the samples are calculated. Three samples are prepared for each batch of testing, so that the repeatability of results can be ensured. A series of isotropic compression tests are conducted at the rate of $40 \mathrm{kPa}$ per hour.

\section{Results and discussion}

Three water content, $139 \%, 104 \%$ and $78 \%$ are used in this study, which approximately correspond to $1.7,1.3$, 1.0 times the liquid limit of clay. The notation used in this study, for example, 1.3-30-7 10S, refers to a specimen with water content 1.3 times the liquid limit of kaolin clay $(104 \%), 30 \%$ cement content, 7 days of curing with $10 \%$ sand content. 


\subsection{Isotropic compression}

The results obtained from isotropic compression study are shown in Fig. 2. The specific volume is calculated from void ratio. Unlike conventional untreated clay, the solids phase of cemented clay consists of both clay and hardened cement paste. Hence, a composite specific gravity of 2.69 is used to calculate the void ratio of cemented samples.
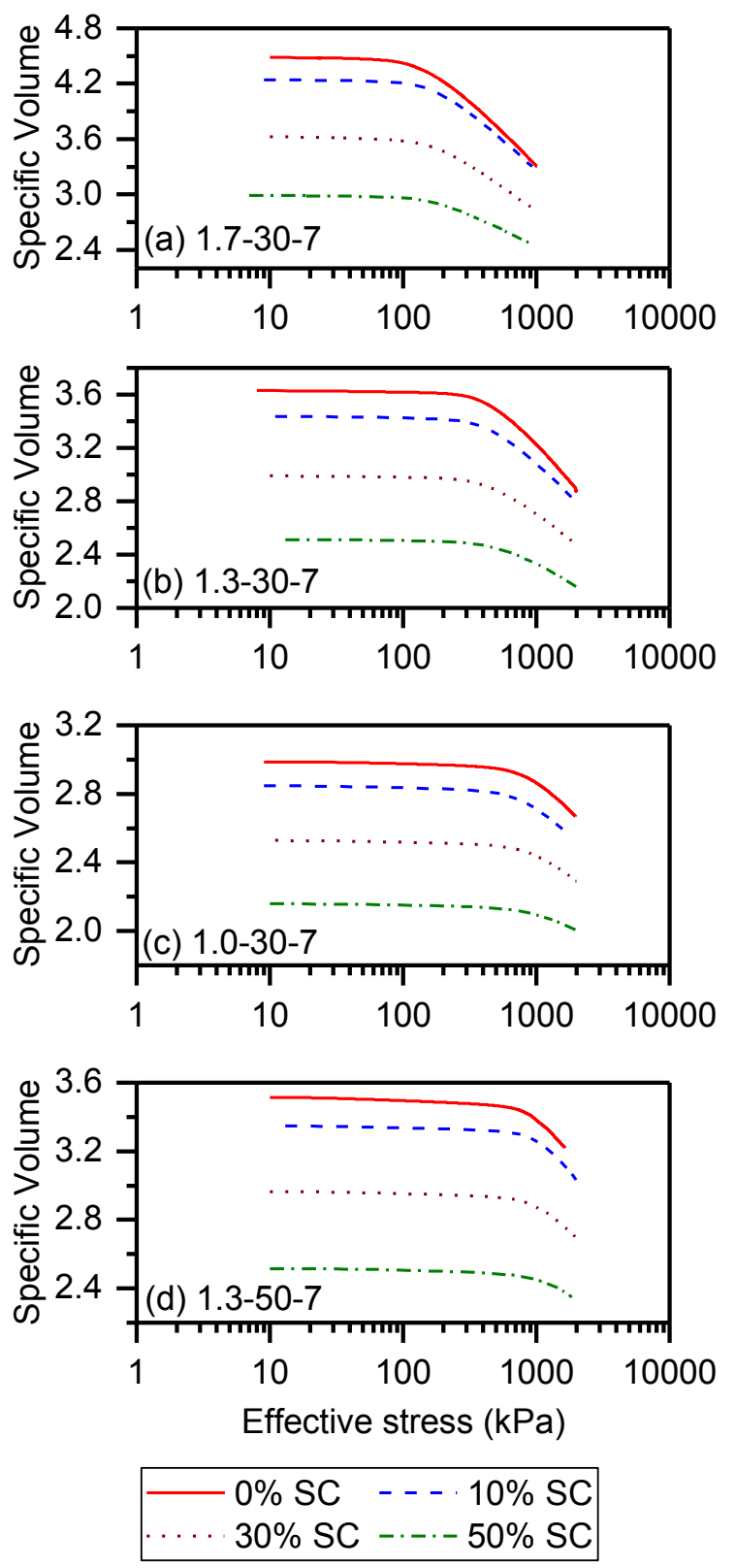

Fig. 2. Specific volume versus isotropic confining pressure for various sand content and water content.

Samples with higher water content have highly porous structure which leads to high specific volume as shown in Fig. 2. The samples are assumed to be fully saturated as they are cured under water. The change in specific volume before yielding is negligible as the cementation controls the compressibility of the samples.

\subsection{Yield stress}

Conventionally, yielding is defined as the stress where plastic strains starts $[28,29]$. In structured soils, yielding can be clearly observed because of an abrupt decrease in compression curve. This point in structured soil where the breakage of cementitious bonds starts is defined as a primary yielding. In literature, researchers have proposed various methods to identify the onset of the primary yielding. A commonly used method was proposed by Rotta et al. [30], which is that yielding is identified as the point where the compression curve starts to deviate from the linear behaviour. Using this definition, the variation of yield points for various mixtures considered in this study is shown in Fig. 3.

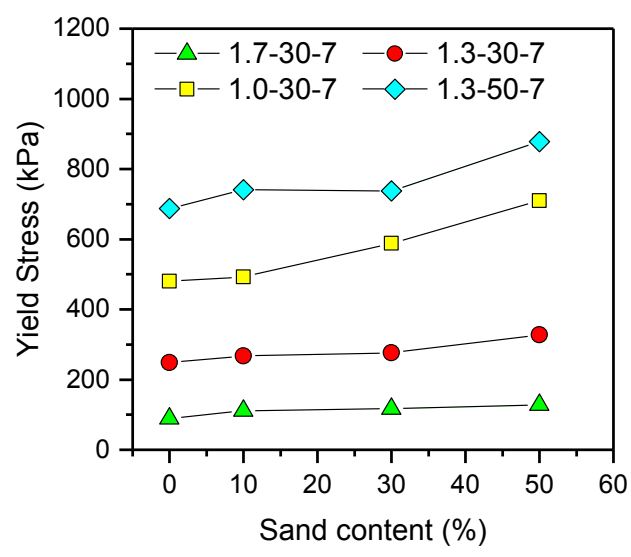

Fig. 3. Variation of yield points with sand content.

The yield stress (YS) increases with reduction in water content and increases with increase in cement content. Reduction in water or increase in cement leads to a less porous structure of soil matrix and a denser cementitious product. Hence higher mean effective stress is required for the loss of structure due to cementation.

For $30 \%$ cement content, the yield point increases slightly up to $10 \%$ sand content and then increases continuously till $50 \%$ sand content. Up to $10 \%$ sand content, the sand is randomly distributed in the cemented clay matrix to cause any significant influence on the yield stress. The increase in yield stress due to the presence of sand is more pronounced in less porous and densely cemented sample (lower water content or higher cement content)

Fig. 4 shows the variation of yield stress with the ratio of water to sum of clay and cement ratio. From Fig. 4 , it can be inferred that irrespective of the sand content, the yield stress reduces with increase in 'water' to 'clay + cement' ratio. The rate of reduction in yield stress increases with increase in sand content. As discussed earlier, in cemented binary mixture study, the ratio of water to sum of clay and cement is a better parameter to examine the effect of sand in cemented clay matrix. 


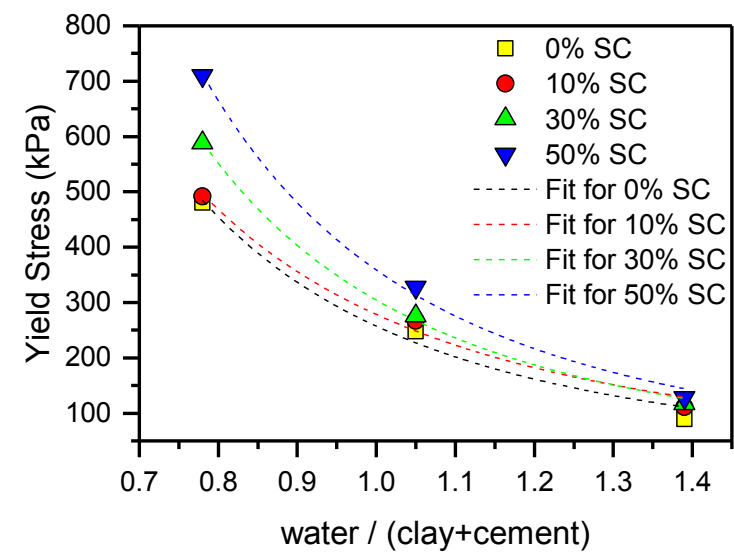

Fig. 4. Variation of yield stress with 'water' to 'clay + cement' ratio.

A power function is used to capture the reduction of yield stress with the ratio of water to combined sum of clay and cement as follows.

$Y S=\alpha / W^{\beta}$ for 0 to $50 \% \mathrm{SC}$

where $W$ is the ratio of water to combined sum of clay and cement and SC is sand content. $\alpha=257 \mathrm{kPa}, 278$ $\mathrm{kPa}, 304 \mathrm{kPa}$ and $358 \mathrm{kPa}$ for $0 \%, 10 \%, 30 \%$ and $50 \%$ sand content respectively and $\beta=2.55,2.32,2.66$ and 2.76 for $0 \%, 10 \%, 30 \%$ and $50 \%$ sand content respectively.

\subsection{Compression Index}

The variation of compression index $\lambda$ with sand content for various mixtures considered in this study is shown in Fig. 5. The compression index generally reduces with increase in sand content. Sand particles far less compressible than clay particles, hence the overall compressibility of the sample reduces. It is observed that the compression index reduces almost linearly with increase in sand content.

Since the compression index is calculated in the post yield zone, it is influenced mostly by water, sand and clay. Higher water content samples are more porous and show high compression index. Samples with same water content but different cement content have relatively comparable compression indices, indicating that cement content has lesser effect on post yield behaviour.

The compression index shows an increasing trend with post curing void ratio and the variation at a given void ratio falls within a narrow band. From Fig. 6, it can be inferred that the post curing void ratio of the samples primarily governs the compression index of the samples. The post curing void ratio is dependent on the sand content and the water content. Knowing the post curing void ratio would help predict the compression index.

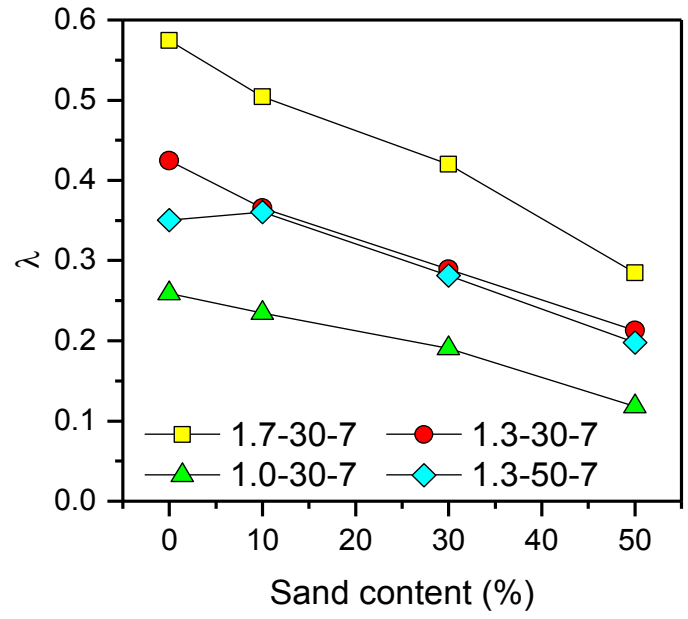

Fig. 5. Variation of compression index $(\lambda)$ with sand content.

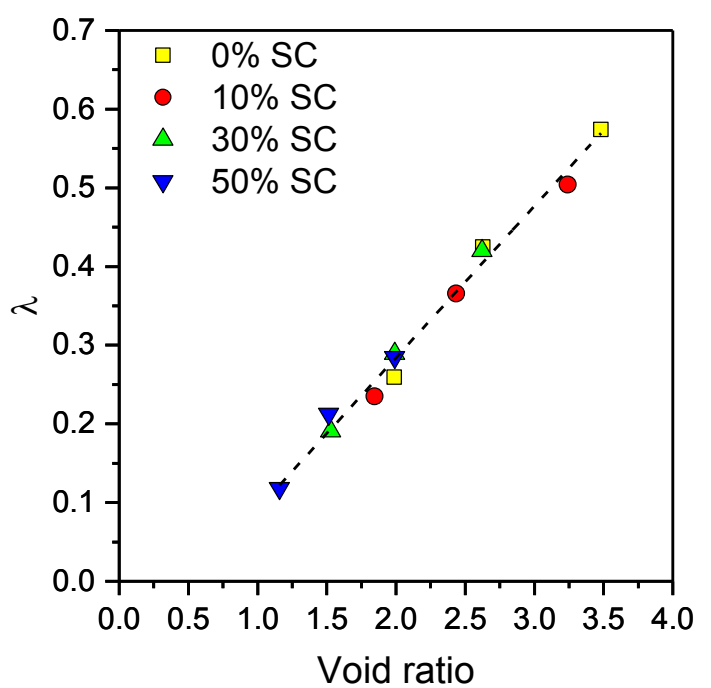

Fig. 6. Variation of compression index with void ratio.

\section{Conclusion}

This paper studied the effect of sand in a cemented clay matrix. It was noted that the use of free water to cement does not clearly delineate the effect of sand in a cemented binary mixture.

1. To capture the effect of sand in cemented clay matrix, new definitions are proposed for water content and cement content: (a) water content defined as the ratio of water to combined sum of clay and cement and (b) cement content defined in terms of mass of clay. The sand added to the cemented clay replaces equal proportions of water, clay and cement.

2. For a given ratio of water to combined sum of clay and cement, the yield stress increased with increase in sand content. A power function can be used to capture this variation of yield stress.

3. The compression index reduced linearly with sand content, as sand is far less compressible than clay. Cement content had little influence on the compression index, while water content and sand content primarily determined the compression index. 
The presence of sand affects the compression index more than the isotropic yield stress.

4. Irrespective of sand content, cement content, and water content, the compression index reduced with reduction in post curing void ratio. The variation of compression index at a given post curing void ratio was within a narrow band.

This research was supported by the Singapore Ministry of Education (MOE), Award No. R-302-000-194-114.

\section{References}

1. S. Thevanayagam, T. Shenthan, S. Mohan, and J. Liang, J. Geotech. Geoenvironmental Eng. 128, 849 (2002).

2. R. Salgado, P. Bandini, and A. Karim, J. Geotech. Geoenvironmental Eng. 126, 451 (2000).

3. H. Choo, W. Lee, and C. Lee, KSCE J. Civ. Eng. 21, 2152 (2016).

4. J. A. H. Carraro, M. Prezzi, and R. Salgado, J. Geotech. Geoenvironmental Eng. 135, 1167 (2009).

5. H. Choo and S. E. Burns, Soil Dyn. Earthq. Eng. 60, 44 (2014).

6. H. Choo and S. E. Burns, Granul. Matter 17, 567 (2015).

7. A. H. Kamruzzaman, S. H. Chew, and F. H. Lee, J. Geotech. Geoenvironmental Eng. 135, 573 (2009).

8. S. H. Chew, A. H. M. Kamruzzaman, and F. H. Lee, Proc. Inst. Civ. Eng. Improv. 10, 113 (2006).

9. S. H. Chew, A. H. M. Kamruzzaman, and F. H. Lee, J. Geotech. Geoenvironmental Eng. 130, 696 (2004).

10. S. Horpibulsuk, N. Miura, and T. S. Nagaraj, Geotechnique 53, 439 (2003).

11. F.-H. Lee, Y. Lee, S.-H. Chew, and K.-Y. Yong, J. Geotech. Geoenvironmental Eng. 131, 178 (2005).

12. S. Horpibulsk, R. Rachan, A. Suddeepong, and A. Chinkulkijniwat, Soils Found. 51, 239 (2011).

13. S. Subramanian, Q. Khan, and T. Ku, Constr. Build. Mater. 202, 308 (2019)

14. S. Subramanian, S.-W. Moon, J. Moon, and T. Ku, J. Mater. Civ. Eng. 30, 04018313 (2018).

15. N. C. Consoli, R. A. Quiñónez, L. E. González, and R. A. López, J. Mater. Civ. Eng. 29, 4016277 (2016).

16. A. Diambra, L. Festugato, E. Ibraim, A. P. da Silva, and N. C. Consoli, Soils Found. 58, 199 (2018).

17. S. Horpibulsuk, D. T. Bergado, and G. A. Lorenzo, Geotechnique 54, 151 (2004).

18. K. Uddin, Strength and Deformation Behavior of Cement-Treated Bangkok Clay, Asian Institute of Technology, Bangkok, Thailand, 1994.

19. T. S. Nagaraj, N. S. Pandian, and P. S. R. Narashimha Raju, Geotechnique 48, 281 (1998).

20. D. Wang and L. Korkiala-Tanttu, Eng. Geol. 214, 20 (2016)
21. H. Xiao, F. H. Lee, and K. G. Chin, Soils Found. 54, 488 (2014).

22. Y.-T. Pan, H.-W. Xiao, F.-H. Lee, and K.-K. Phoon, Geotech. Test. J. 39, 695 (2016).

23. F. Schnaid, P. D. M. Prietto, and N. C. Consoli, J. Geotech. Geoenvironmental Eng. 127, 857 (2001).

24. K. Yao, H. Xiao, D.-H. Chen, and Y. Liu, Géotechnique 1 (2018).

25. R. D. V. Flores, G. Di Emidio, and W. F. Van Impe, Geotech. Test. J. 33, 62 (2009).

26. S. C. Chian, Y. Q. Chim, and J. W. Wong, Géotechnique 67, 31 (2016).

27. S. Subramanian and T. Ku, in 30th KKHTCNN Symp. Civ. Eng. (2017).

28. J. B. Burland, Géotechnique 40, 329 (1990).

29. T. Ku and P. W. Mayne, Eng. Geol. 152, 122 (2013).

30. G. V Rotta, N. C. Consoli, P. D. M. Prietto, M. R. Coop, and J. Graham, Geotechnique 53, 493 (2003). 